\title{
IMPROVEMENTS TO LEAD-EXTRUSION DAMPER TECHNOLOGY
}

\author{
W.J. Cousins ${ }^{1,2}$, T.E. Porritt ${ }^{1}$
}

\begin{abstract}
SUMMARY
Lead-extrusion dampers are energy absorbing devices that have been designed to provide damping for seismic isolation systems. One type, called the constricted tube damper, has been manufactured for several applications in New Zealand. High manufacturing costs and some performance considerations associated with the damper led to consideration of an alternative design known as the bulged shaft damper. This report describes tests carried out on bulged shaft dampers of two sizes, $100 \mathrm{kN}$ and $700 \mathrm{kN}$ yielded force. Results show that the bulged shaft design of damper can be expected to perform well during major seismic events, including mainshock/aftershock sequences.
\end{abstract}

\section{INTRODUCTION}

The lead-extrusion damper is an energy absorbing device that converts mechanical energy to heat through the cyclic deformation of lead. Since being invented in the early 1970's [6], it has been used in New Zealand to provide damping for seismic isolation systems in 3 bridges and one 10-storey building $[3,5,7,8]$. Although it is somewhat more costly than a companion device, the lead-rubber bearing [4], it does have particular application where coulomb damping is required, or when displacements greater than about $\pm 250 \mathrm{~mm}$ have to be accommodated.

There are two basic versions of the lead-extrusion damper. In one version, called the "constricted tube" damper, a billet of lead is forced to extrude back and forth through an orifice that is formed by an annular constriction in the surrounding tube (Fig. 1(a)). In the other version, the "bulged shaft" damper, the orifice is created by a bulge on a central shaft that moves back and forth through the lead billet (Fig. 1(b)).

Prototypes of both forms of the damper were tested [6,7], and the constricted tube version was selected for manufacture. Dampers with load and stroke capacities of $150 \mathrm{kN} / \pm 200 \mathrm{~mm}$ were installed beneath the Bolton St. and Aurora Tce. motorway overpass bridges in Wellington, and beneath the Bannockburn Bridge in Central Otago. Larger dampers, $250 \mathrm{kN} / \pm 400 \mathrm{~mm}$, were used in the base-isolation system for the new Central Police Station in Wellington [1].

The constricted tube damper proved to be a difficult and costly device to manufacture. Experience gained during the

\footnotetext{
1 Institute of Geological and Nuclear Sciences, Lower Hutt

2 Member
}

manufacturing process convinced the authors that the bulged shaft damper was potentially a much more easily manufacturable device than the constricted tube damper, and that both cost savings and improvements in performance were possible. It also became clear that economies of scale were significant.

\section{ADVANTAGES OF THE BULGED SHAFT DESIGN}

For a lead-extrusion damper to show consistent and predictable performance the sliding lead-steel interfaces must be well lubricated, and if the integrity of the lubricant film is to be maintained at the high pressures required for extrusion, for many cycles of operation, then the finish on the steel surfaces must be of high quality. It is relatively easy to produce a suitable finish on the outside surface of a shaft, even one of variable cross section as in a bulged shaft damper, but producing a constricted tube with a high quality finish on the inside surface is very difficult. Each of the constricted tubes in the manufactured dampers had to be made in three sections, utilizing lengths of honed bore steel tubing for the two parallel-sided sections at each end and a separate, machined and polished, orifice section. Joining the three parts and removing surface irregularities at the joints were very costly manufacturing steps. In contrast, a shaft with a bulge on it is easily machined from a solid bar and surface finishing also is easy. The external tube for a bulged shaft damper too can be made from a single piece of honed bore steel tubing.

A second unsatisfactory feature that was common to both versions of the damper was the use of machined lead billets. Lead is a difficult material to machine to close tolerances and as a consequence each core in the manufactured dampers had to be made in two or more segments, and each segment was machined on all faces. This was unsatisfactory on two counts, (1) the machining was costly, and (2) the passage of the joints in the lead core through the orifice gave 
(a) constricted tube type

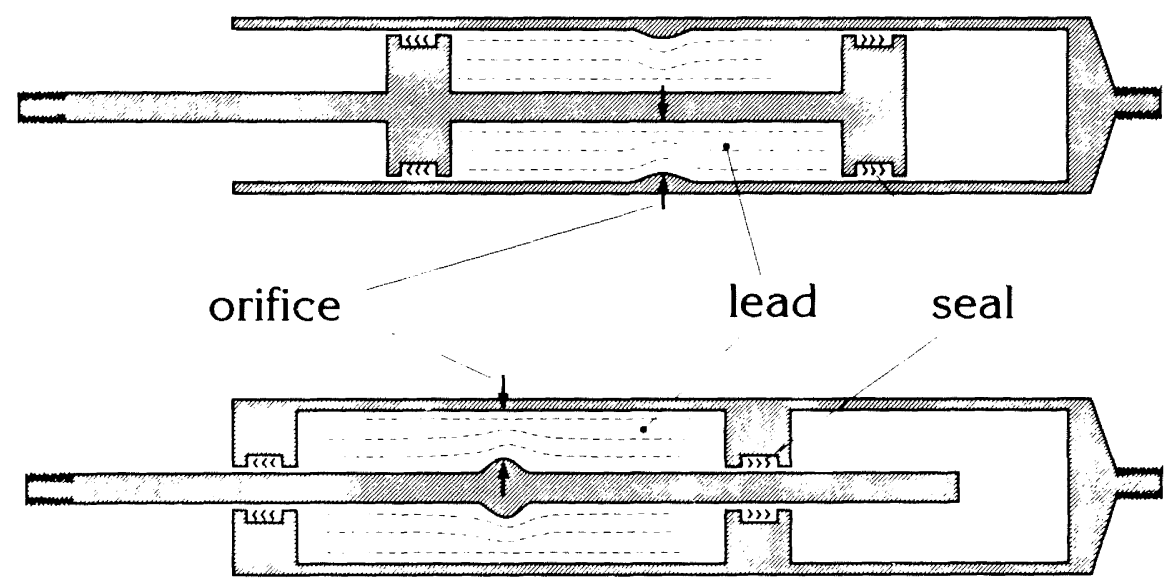

(b) bulged shaft type

Figure 1: Longitudinal sections of two versions of the lead-extrusion damper,

(a) constricted tube type, and

(b) bulged shaft type.

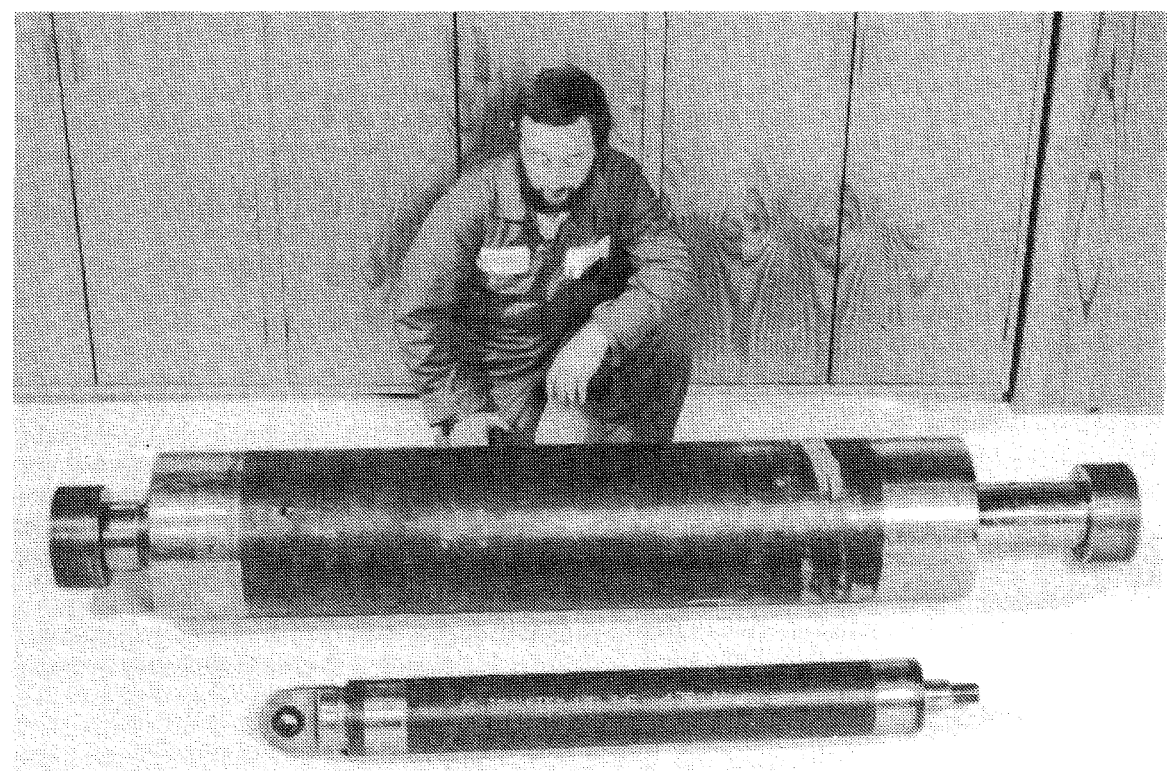

Figure 2: $\quad 100 \mathrm{kN}$ and $700 \mathrm{kN}$ bulged shaft lead-extrusion dampers. 
rise to "ripples" in the hysteresis loops of the dampers [3,5]. The solution adopted was to improve the technique for the initial casting of the lead billets, which subsequently reduced both the machining costs and the segmentation of the core.

\section{PROPERTIES OF THE BULGED SHAFT DAMPER}

Bulged shaft dampers with force capacities of $100 \mathrm{kN}$ and $700 \mathrm{kN}$ (Fig. 2 and Table 1) were constructed and subjected to dynamic mechanical testing in order to establish the force and energy absorbing characteristics, the effects of rate, and as far as practicable, the lifetime. The testing consisted of applying sinusoidal displacements to one end of each damper while the other end was held in a fixed position. The applied displacements and the resulting forces were recorded (a) with an X-Y recorder as load-displacement plots, and (b) digitially with a data logger as load-time and displacement-time files. In both cases the testing rate and stroke (Table 1) were determined largely by the capacities of the testing machines.

The $700 \mathrm{kN}$ damper was subjected to 20 test runs, with varying numbers of cycles per run from 1 to 20 , and with rest periods between the runs of 3 minutes to 5 days. In total it accumulated 114 cycles. The $100 \mathrm{kN}$ damper damper was treated similarly for a total of 250 cycles.

In many respects the properties of the 100 and $700 \mathrm{kN}$ bulged shaft dampers were similar to those of the earlier prototype bulged shaft and constricted tube dampers $[3,5,7]$. The hysteresis loops were generally rectangular, the operating force remained relatively constant between reversals, and the operating force and energy absorption decreased as the damper warmed up during continuous cycling (Fig. 3). The average energy absorption over the first three cycles was $>80 \%$ of the nominal calculated for a rectangular hysteresis loop based on the peak force and the total test stroke, and the minimum peak force during any of the first 5 cycles was $>75 \%$ of the peak force. In these respects, therefore, the two bulged shaft dampers met the performance criteria specified for the manufactured constricted tube dampers $[2,3]$.

There were however some significant differences between the performances of the current bulged shaft dampers and those of the previously tested constricted tube dampers. Firstly, as anticipated, the operating force was more uniform than that previously reported $[3,5]$, and lacked the "ripples" caused by passage through the orifice of construction joints in the lead billets. The lead core of each bulged shaft damper contained one construction joint, necessary for assembly, but the joint was located as close as possible to the end of the core and away from the portion that was actively extruded during cycling. The lead cores of the manufactured constricted tube dampers all had construction joints within the "active" region.

The effect of extrusion rate on the performance of extrusion dampers also appeared to need some reinterpretation. It had been found previously that the relation between the extrusion force $\mathbf{F}$ and the extrusion speed $\mathbf{v}$ could be written

$$
\mathbf{F}=\mathbf{a} \mathbf{v}^{\mathbf{b}},
$$

where $\mathbf{a}$ and $\mathbf{b}$ were constants. The constant $\mathbf{b}$ had $\mathbf{a}$ value of 0.12 for extrusion speeds below $10^{-4} \mathrm{~m} / \mathrm{s}$ and 0.03 at speeds above $10^{-4} \mathrm{~m} / \mathrm{s}$ [7]. However, the data that formed
Table 1: Dimensions of the test dampers, and test conditions

\begin{tabular}{||c|c|c||}
\hline \hline $\begin{array}{c}\text { Nominal Force }(\mathrm{kN}) \\
\begin{array}{c}\text { Stroke capacity } \\
(\mathrm{mm})\end{array}\end{array}$ & 100 & 700 \\
\hline Length $(\mathrm{m})$ & 1.4 & \pm 225 \\
\hline Tube OD $(\mathrm{mm})$ & 127 & 305 \\
\hline Tube bore $(\mathrm{mm})$ & 102 & 254 \\
\hline Test stroke $(\mathrm{mm})$ & \pm 125 & \pm 150 \\
\hline Max. test rate $(\mathrm{Hz})$ & 0.5 & 0.033 \\
\hline
\end{tabular}

the basis for this finding all had been referenced to the force obtained at a speed of $1.7 \times 10^{-4} \mathrm{~m} / \mathrm{s}(1 \mathrm{~cm} /$ minute), with the relationship at lower speeds being determined largely from measurements on bulged shaft dampers and the relationship at higher speeds from measurements on constricted tube dampers. The observed trends could have been ascribed to differences between the two types of damper, and merging data from tests on the $100 \mathrm{kN}$ and $700 \mathrm{kN}$ bulged shaft dampers with the previous data set tends to support this assertion (Figure 4). The " $b$ " values obtained from the entire data sets are 0.12 for the bulged shaft dampers and 0.03 for constricted tube dampers.

Only relatively limited information has been published about the force and energy absorption characteristics of the leadextrusion damper during multi-cycle running, such as might be required during a large earthquake, or its potential response to repeated earthquake shocks. Plots of hysteresis loops have ranged from single cycles [7] to 6 cycles [3,9], and very recently, 10 cycles [8]. In so far as repeated tests are concerned, Robinson and Greenbank [7] cycled a $15 \mathrm{kN}$ damper for 3400 cycles between between two instrumented test runs and found that the performance of the damper was not impared by what was a most severe test. Robinson and Cousins [5] showed that a 10 year period of idleness did not degrade the performance of a $150 \mathrm{kN}$ damper, but in tests of relatively few cycles.

There appears to be little precise published information giving the likely demand on a damper during a major earthquake. Robinson [7] has stated that during a major earthquake a lead-extrusion damper could be expected to undergo $\sim 10$ major cycles. Charleson et al [1] modelled the response of a base-isolated 10 -storey building to $1.4 \mathrm{x}$ the $\mathrm{El}$ Centro $1940 \mathrm{~N}-\mathrm{S}$ component and generated a displacement time history that contained approximately 6 irregular cycles in a $12 \mathrm{~s}$ period. The base isolation system incorporated leadextrusion dampers.

The above scale factor of $1.4 \mathrm{x}$ was specified to simulate a 450 year return period spectrum, for which the building in question was required to remain fully functional. An additional requirement was that the building should not collapse in a larger, 1000 year, earthquake that was simulated by (among others) $1.7 x$ the El Centro $1940 \mathrm{~N}-\mathrm{S}$ component. It seems likely that the displacement time history for the 1000 year event would contain $\sim 10$ significant cycles, which in turn suggests that it would be reasonable to expect a prototype 

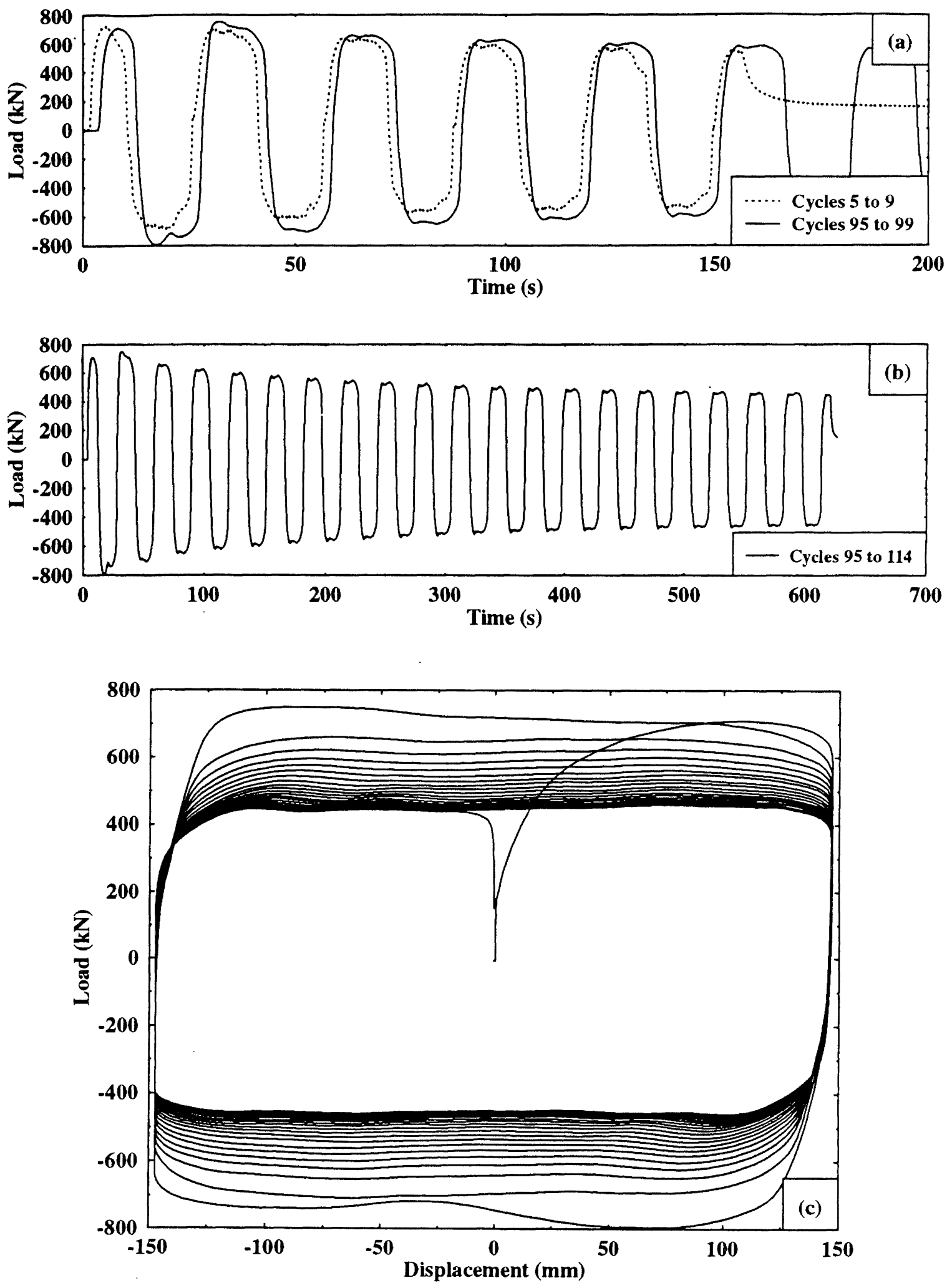

Figure 3: Force characteristic of a $700 \mathrm{kN}$ bulged shaft lead-extrusion damper in response to applied sinusoidal displacements of $\pm 150 \mathrm{~mm} / 0.033 \mathrm{~Hz}$

(a) Comparison of the load-time histories for the first 5-cycle test run and the finst 5 cycles of the final test num.

(b) load-time history for all of the final test rum, and

(c) load-displacement loops for the final test run. 


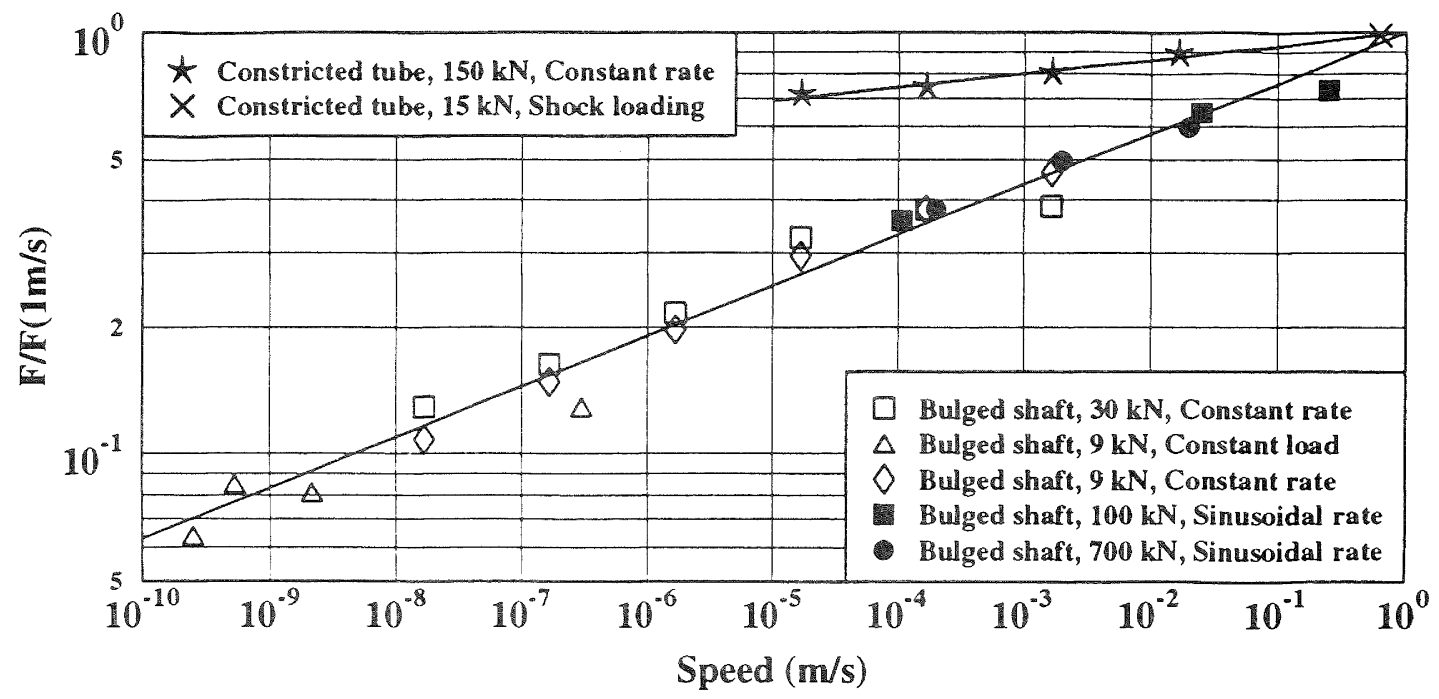

Figure 4: $\quad$ Rate dependence of extrusion energy absorbers. Open symbols represent data adapted from [7], and filled symbols data from the testing of the 100 and $700 \mathrm{kN}$ bulged shaft dampers. The forces are referenced to the force estimated for an extrusion speed of $1 \mathrm{~m} / \mathrm{s}$.

damper to perform reliably during a test of about 20 continuous cycles.

Large shallow earthquakes are nearly always accompanied by aftershocks, and typically the largest aftershock will be 1 or 2 magnitude units smaller than the mainshock [10]. As an example, the 1968 Inangahua mainshock of magnitude 6.7 was followed by aftershocks of magnitude 5.7 and 5.4 after periods of 27 hours and 7 days respectively. The 1987 Edgecumbe earthquake had a magnitude of 6.1 , and the largest aftershock, with magnitude 5.6, followed the mainshock by 8 minutes. The peak ground accelerations recorded at a site $21 \mathrm{~km}$ from the epicentres were $0.33 \mathrm{~g}$ and $0.07 \mathrm{~g}$ respectively. Thus a realistic, severe, scenario could be for a damper to undergo $~-10$ large-stroke cycles during a major event, followed 10 minutes later by a few cycles during a large aftershock, and 24 hours later by a few more cycles during another large aftershock.

It was to span the above possibilities that the 100 and $700 \mathrm{kN}$ bulged shaft dampers were subjected to a variety of multicycle tests at close to full stroke with a variety of rest periods between the tests.

Test runs of 20 cycles (Figs 3 and 5) appeared to be well within the capacity of the damper. The operating force decreased with continued cycling as the lead core warmed up, but after 15 to 20 cycles the rate of decrease was small and the damper appeared to be approaching a steady state. Fitting an exponential-decay type relation to the energy absorption data for the $700 \mathrm{kN}$ damper, the dashed line shown in Figure 5, gave a predicted steady-state energy absorption/cycle that was $65 \%$ of the cycle 1 energy absorption.

The potential response of the dampers to closely spaced mainshock-aftershock sequences was investigated in extreme fashion by subjecting each of the dampers to 12 consecutive test runs. For the $700 \mathrm{kN}$ damper the series of tests comprised 10 runs each of 5 cycles followed by two runs of 20 cycles. There was an interval of 3 minutes between runs 1 and 2, 10 minutes between runs 2 and 3, 30 minutes between runs 3 and 4 and 120 minutes between runs 4 and 5 . The damper was then rested overnight ( 21 hours) and the series of 5 test runs was repeated. The rest periods preceeding the final two runs of 20 cycles each were 21 and 24 hours respectively.

The results, Figure 5, show clearly that the damper can be expected to cope well with either repeated major events or a mainshock/aftershock sequence. If the time interval between major shocks is more than about 20 hours the performance of the damper will be as rated for both events. If however the time interval is only a few hours or less, the damper will not have returned to ambient temperature by the time of the second shock and both the force and energy absorption will be lower than rated. In terms of energy absorption, the results suggest that to a good approximation events requiring -5 cycles of response each and which are separated by only a few minutes can be regarded as contiguous, whilst for events separated by 10 or more minutes the energy absorbing capacity of the damper will be $75 \%$ or more of the initial value.

The repeatability in performance from one run to another, under similar conditions, is excellent.

The $100 \mathrm{kN}$ damper also was subjected to a series of 12 test runs but over a three day period and under somewhat different conditions. Each run consisted of 10 cycles, there were 4 test runs per day, and the rest periods between the runs ranged from 5 to 30 minutes. In general terms the performance of the $100 \mathrm{kN}$ damper was similar to that of the $700 \mathrm{kN}$ damper. The main difference was that after being cycled the $100 \mathrm{kN}$ damper recovered more rapidly than the $700 \mathrm{kN}$ damper, and after 10 minutes the energy absorping capacity was $90 \%$ of the initial value (Table 2 ). 


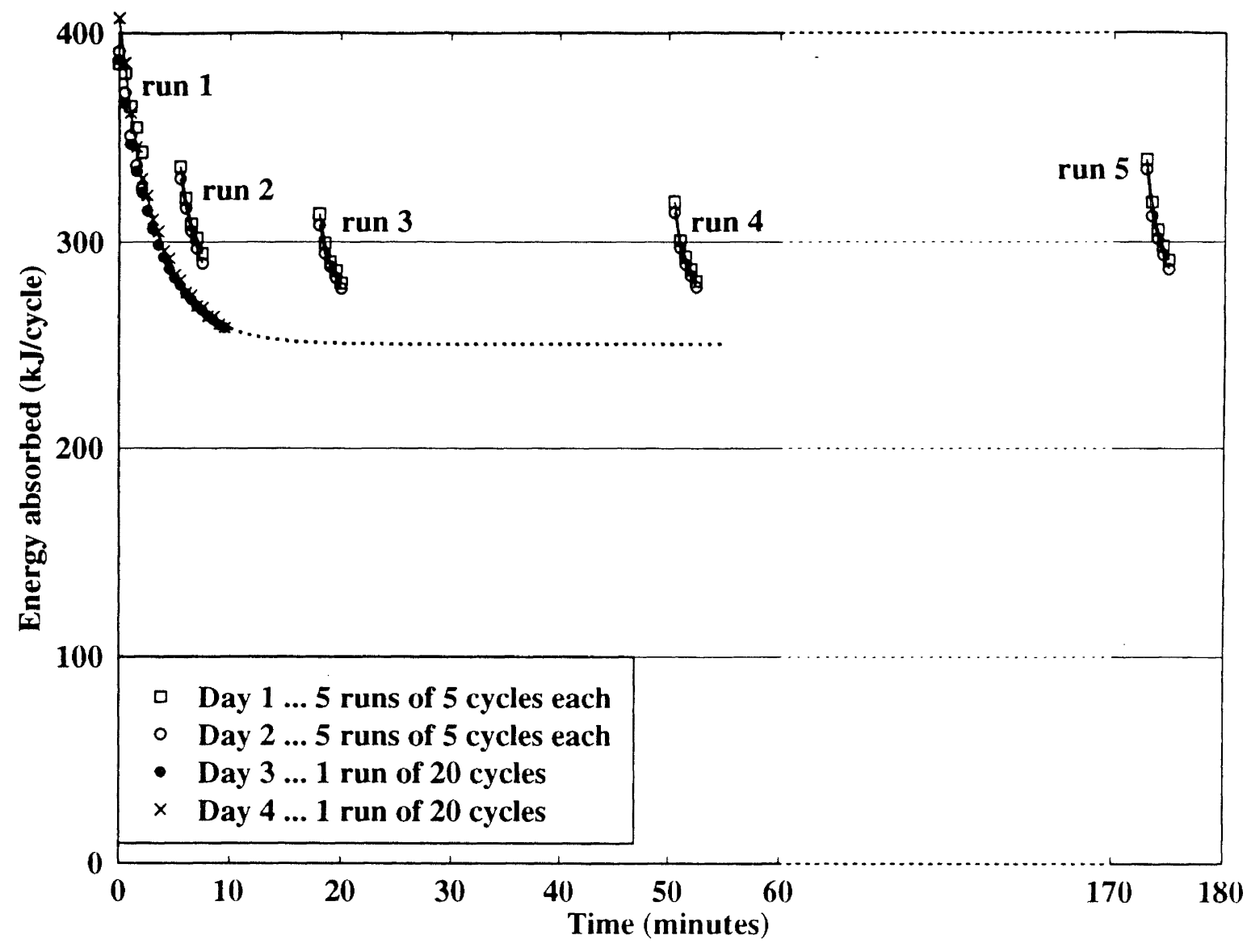

Figure 5: $\quad$ Effect of prior cycling history on energy absorbing capacity for a $700 \mathrm{kN}$ bulged shaft damper cycled at $\pm 150 \mathrm{~mm} / 0.033 \mathrm{~Hz}$ The plots, which are described in the text, illustrate (a) the rate of recovery of the damper and $(b)$ the repeatability. The dashed line is an extrapolation of an exponential-decay function fitted to the 20-cycle test data.

Table 2: Relative energy absorption during 12 consecutive test runs of a $100 \mathrm{kN}$ bulged shan lead-extrusion damper. Each test run consisted of 10 cycles of $\pm 125 \mathrm{~mm}$ displacement at $0.5 \mathrm{~Hz}$, and each day there were 4 runs with the rest period between consecutive runs as indicated.

\begin{tabular}{||c|c|c|c|c|c||}
\hline \multirow{2}{*}{ Day } & \multirow{2}{*}{$\begin{array}{c}\text { Rest period } \\
\text { between runs } \\
\text { (minutes) }\end{array}$} & \multicolumn{4}{|c||}{ Energy absorbed (\%) } \\
\cline { 3 - 6 } & & Run 1 & Run 2 & Run 3 & Run 4 \\
\hline 1 & 5 & 100 & 88 & 82 & 79 \\
\hline 2 & 10 & 102 & 90 & 84 & 81 \\
\hline 3 & 30 & 103 & 95 & 91 & 89 \\
\hline
\end{tabular}


A final observation is that the initial force capacity, and hence initial energy absorption per cycle, measured during tests that commenced with the dampers at ambient temperature, gradually increased with increasing number of prior cycles. The changes were approximately $10 \%$ per 100 cycles (Fig. 3(a)), which is not significant for situations in which a damper is unlikely to experience more than 10 to 20 cycles during its entire lifetime.

\section{CONCLUSIONS}

Two sizes of bulged shaft lead extrusion damper have been designed, manufactured, and tested. The force and stroke capacities were $100 \mathrm{kN} / \pm 190 \mathrm{~mm}$ and $700 \mathrm{kN} / \pm 225 \mathrm{~mm}$.

Manufacturing and assembly has proved to be simpler than with the constricted tube design, and some costly manufacturing processes have been avoided.

An improved method for manufacturing the lead core has resulted in a more uniform operating force over the length of stroke than for the dampers previously described.

There is evidence that the empirical relationship between extrusion force and extrusion speed previously postulated for both constricted tube and bulged shaft dampers may consist of separate relationships applicable to each damper type.

Results of extensive testing demonstrate that the bulged shaft damper design can be expected to cope well with either repeated major seismic events or a mainshock/aftershock sequence, without any significant deterioration in performance.

\section{ACKNOWLEDGEMENTS}

The authors gratefully acknowledge the contributions made by the following persons;

C R Gannon (of New Zealand Institute for Industrial Research) (a) for constructing the dampers, and (b) for many helpful suggestions during the design of the dampers,

J Babor (of the Institute of Geological and Nuclear Sciences Ltd) for assistance with mechanical design of the dampers,

G Beattie and D Jacks (of Works Services Corporation) for carrying out the testing of the $700 \mathrm{kN}$ damper,

W H Robinson (of New Zealand Industrial for Industrial Research) for helpful discussions and encouragement, and

A Van Dyk and staff, for excellent workmanship in the manufacture of the lead cores.

\section{REFERENCES}

1. Charleson, A.W., Wright, P.D., Skinner, R.I., 1987 "Wellington Central Police Station, base isolation of an essential facility", Proc. Pacific Conference on Earthquake Engineering, 5-8 August 1987, Wairakei, New Zealand, 2:377-388.

2. Cousins, W. J., 1988, "Report on weld inspection and mechanical testing of lead-extrusion dampers for Bannockburn bridge", Physics and Engineering Laboratory, DSIR, Confidential Client Report.

3. Cousins, W.J., Robinson, W.H., McVerry, G.H. 1992 "Recent developments in devices for seismic isolation", Bulletin of the New Zealand National Society for Earthquake Engineering, 25(3): 167-174.

4. Robinson, W.H., 1982, "Lead-rubber hysteretic bearings suitable for protecting structures during earthquakes", Earthquake Engineering and Structural Dynamics, 10(4):593-604.

5. Robinson, W.H., Cousins, W.J., 1988, "Lead dampers for base isolation", Proceedings of the Ninth World Conference on Earthquake Engineering, August 2-9, 1988, Tokyo-Kyoto, Japan, (Vol VIII): 427-432.

6. Robinson, W.H., Greenbank, L.R., 1975, "Properties of an extrusion energy absorber", Bulletin of the New Zealand National Society for Earthquake Engineering, 8(3): 187-191.

7. Robinson, W.H., Greenbank, L.R., 1976, "An extrusion energy absorber suitable for the protection of structures during an earthquake", Earthquake Engineering and Structural Dynamics, 4(3):251-259.

8. Skinner, R.I., Robinson, W.H., McVerry, G.H., 1993, "An Introduction to Seismic Isolation", John Wiley \& Sons, Chichester.

9. Skinner, R.I., Tyler, R.G., Heine, A.J., Robinson, W.H., 1980, "Hysteretic dampers for the protection of structures from earthquakes", Bulletin of the New Zealand National Society for Earthquake Engineering, 13(1): 22-36.

10. Wesnousky, S.G., Scholz, C.H., Shimanzki, K. Matsuda, T., 1983, "Earthquake frequency distribution and the mechanics of faulting", Journal of Geophysical Research, 88:9331-9340. 